\title{
Correction to: Production efficiency of the bacterial non-ribosomal peptide indigoidine relies on the respiratory metabolic state in S. cerevisiae
}

\author{
Maren Wehrs 1,2,3, Jan-Philip Prahl1,4, Jadie Moon 1,3 ${ }^{1,}$ Yuchen Li ${ }^{1,3}$, Deepti Tanjore ${ }^{1,4}$, Jay D. Keasling 1,3,5,6,7,8,9, \\ Todd Pray ${ }^{1,4}$ and Aindrila Mukhopadhyay ${ }^{1,3,10^{*}}$ (B)
}

\section{Correction to: Microb Cell Fact (2018) 17:193}

https://doi.org/10.1186/s12934-018-1045-1

Following publication of the original article [1], the authors have noted that the standard curve in Additional file 1: Figure S7 is incorrect.

The authors have since corrected the standard curve for Additional file 1: Figure S7 and recalculated the Titers (as $\mathrm{g} \mathrm{L}^{-1}$ ) of the final product Indigoidine.

Please note that by using the corrected standard curve, the titer values in the following figures are altered: Figs. 3, 4 , and 5 .

However, none of the raw measurements have changed, the Figure captions are not affected and the conclusions remain unchanged.
The corrections are provided by this article (please find detailed below).

Statements in the manuscript that refer to the numerical titer values are corrected as follows:

In the abstract, the corrected manuscript should state:

...reaching a maximum titer of $209.9 \mathrm{mg} / \mathrm{L} . .$.

In results on page 6, the corrected manuscript should state:

...reaching $209.9 \mathrm{mg} / \mathrm{L} \ldots$

In conclusions on page 7 , the corrected manuscript should state:

...achieving $209.9 \mathrm{mg} / \mathrm{L} . .$.

(C) The Author(s) 2019. This article is licensed under a Creative Commons Attribution 4.0 International License, which permits use, sharing, adaptation, distribution and reproduction in any medium or format, as long as you give appropriate credit to the original author(s) and the source, provide a link to the Creative Commons licence, and indicate if changes were made. The images or other third party material in this article are included in the article's Creative Commons licence, unless indicated otherwise in a credit line to the material. If material is not included in the article's Creative Commons licence and your intended use is not permitted by statutory regulation or exceeds the permitted use, you will need to obtain permission directly from the copyright holder. To view a copy of this licence, visit http://creativeco mmons.org/licenses/by/4.0/. The Creative Commons Public Domain Dedication waiver (http://creativecommons.org/publicdomain/ zero/1.0/) applies to the data made available in this article, unless otherwise stated in a credit line to the data. 
Degree of respiration

Degree of fermentation
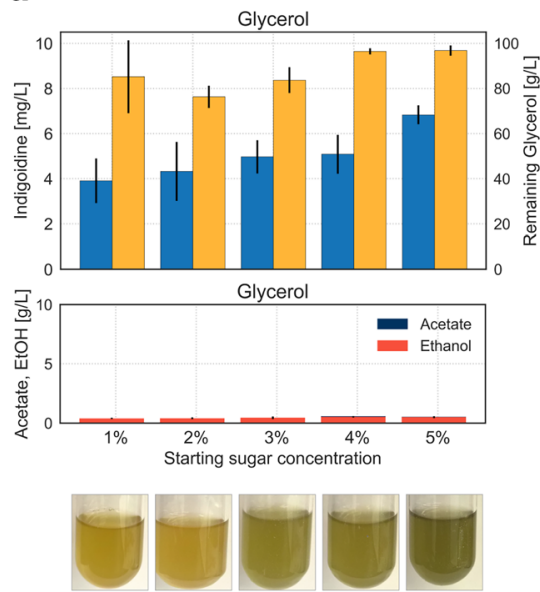

b

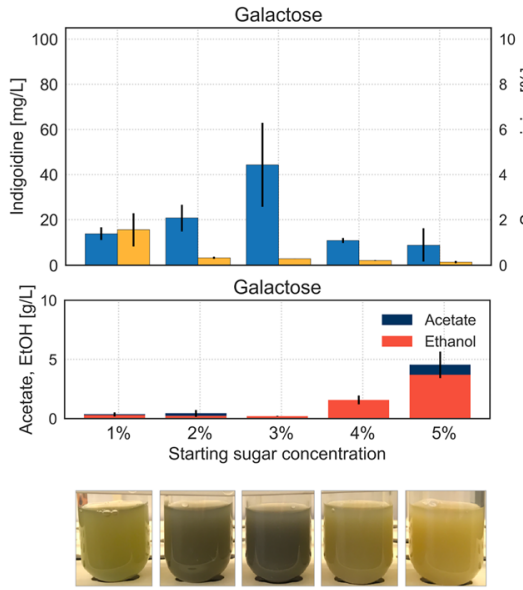

C
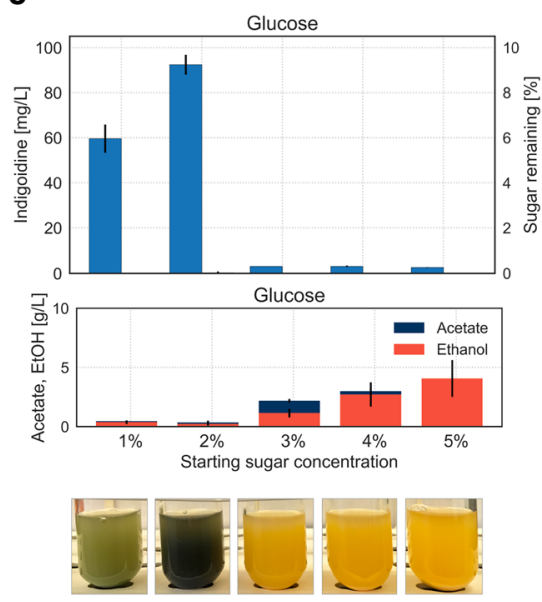

Fig. 3 Phenotype and Titer of BJ5465.sfp.bpsA grown in different carbon sources for 3 days. BJ5465.sfp.bpsA was grown in rich media containing either glycerol (a), galactose (b) or glucose (c) ranging in concentrations from 1 to $5 \%$ as sole carbon source for 3 days. The carbon sources are utilized via different metabolic pathways in S. cerevisiae, namely respiratory for glycerol, mixed respiro-fermentative for galactose and fermentative for glucose. Top: Quantification of indigoidine produced (blue bars) and remaining sugar in percentage (yellow bars) after 3 days of cultivation. Note difference in scale for indigoidine titer in glycerol compared to galactose and glucose. Middle: Quantification of ethanol (red bars), acetate (dark blue bars), and indigoidine (blue bars). Bottom: Representative photographs of respective liquid cultures after 3 days of cultivation. Error bars represent $95 \% \mathrm{Cl}(n=4)$

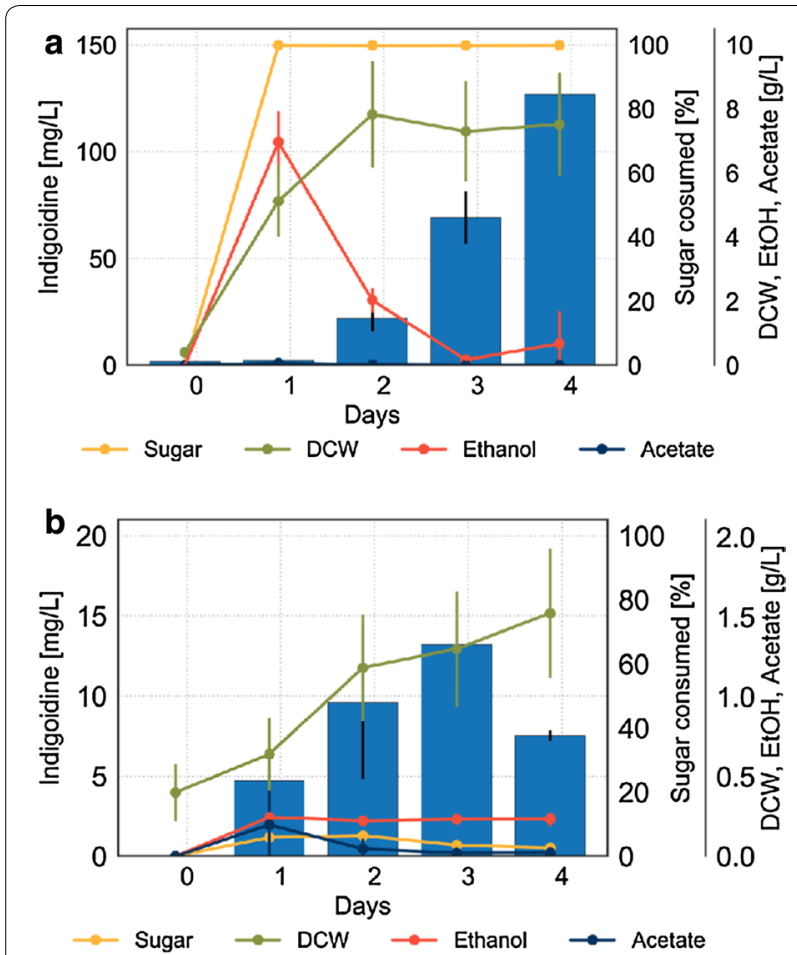

Fig. 4 Cultivation profile of BJ5465.sfp.bpsA in different carbon sources. Concentrations of indigoidine (blue bars), consumed sugar (yellow line), dry cell weight (DCW, green line) and the by-products ethanol (red line) and acetate (dark blue line) are plotted against time for cells grown in a glucose and $\mathbf{b}$ glycerol. Error bars represent $95 \%$ $\mathrm{Cl}(\mathrm{n}=4)$, note difference in scale between $\mathbf{a}$ and $\mathbf{b}$ 

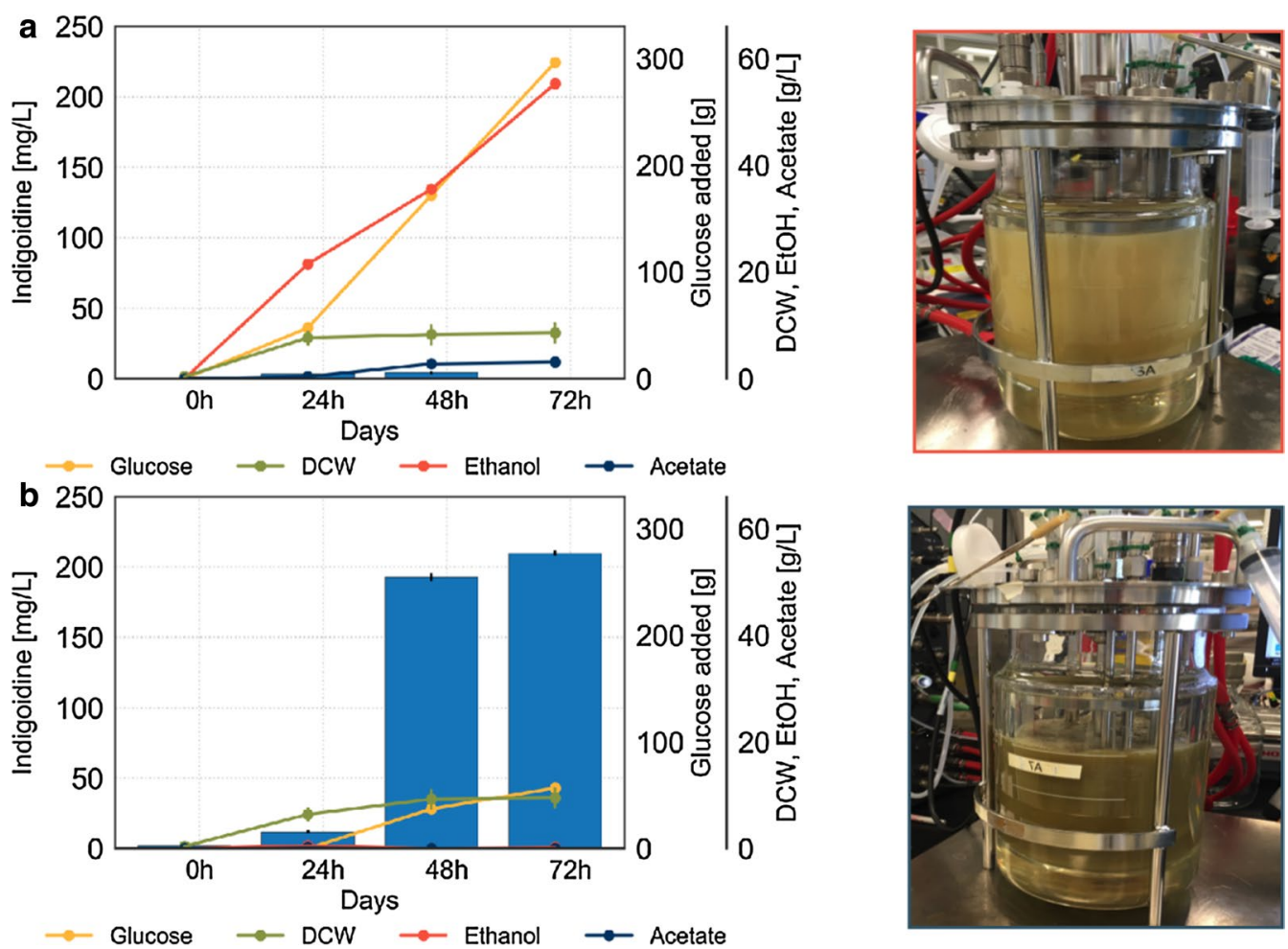

Fig. 5 Regulated environment in $2 \mathrm{~L}$ bioreactor enables control over metabolic state. Fed-batch fermentation of BJ5465.sfp.bpsA with a excess glucose feed or $\mathbf{b}$ signal-based pulse feeding strategy resulting in glucose starvation conditions. Lines represent concentrations of total glucose fed and ethanol and acetate produced; bars represent indigoidine concentration. $\mathrm{N}=3$ technical replicates for indigoidine extraction and DCW measurements. Additional process parameters and gas analysis can be found in Additional file 1: Figures S4 and S5

\section{Supplementary information}

Supplementary information accompanies this paper at https://doi. org/10.1186/s12934-019-1262-2.

Additional file 1: Figure S7. Standard curve of Indigoidine absorbance at $612 \mathrm{~nm}$ in DMSO. Absorbance values were obtained for serial dilutions of purified Indigoidine in DMSO. The equation for the trendline is: $y=0.152 x-0.111 R^{2}=0.9986$. Indigoidine was purified from microbial cultures per Yu et al. (https://doi.org/10.1007/s10295-012-1207-9). Figure shows one representative plot (of three), each with measurements in triplicate.

\section{Author details}

${ }^{1}$ Biological Systems and Engineering Division, Lawrence Berkeley National Laboratory, Berkeley, CA 94720, USA. ${ }^{2}$ Institut für Genetik, Technische Universität Braunschweig, Brunswick, Germany. ${ }^{3}$ Joint BioEnergy Institute, Lawrence Berkeley National Laboratory, Emeryville, CA 94608, USA. ${ }^{4}$ Advanced Biofuels and Bioproducts Process Development Unit, Lawrence Berkeley National Laboratory, Emeryville, CA 94608, USA. ${ }^{5}$ Department of Plant and Microbial Biology, University of California, Berkeley, CA 94720, USA. ${ }^{6}$ Department of Bioengineering, University of California, Berkeley, CA 94720, USA. ${ }^{7}$ Department of Chemical and Biomolecular Engineering, University of California, Berkeley, CA 94720, USA. ${ }^{8}$ The Novo Nordisk Foundation Center for Biosustainability,
Technical University of Denmark, Kongens Lyngby, Denmark. ${ }^{9}$ Synthetic Biochemistry Center, Institute for Synthetic Biology, Shenzhen Institutes for Advanced Technologies, Shenzhen, China. ${ }^{10}$ Environmental Genomics and Systems Biology Division, Lawrence Berkeley National Laboratory, Berkeley, CA 94720, USA.

Published online: 29 December 2019

\section{Reference}

1. Wehrs M, Prahl J-P, Moon J, Li Y, Tanjore D, Keasling JD, Pray T, Mukhopadhyay A. Production efficiency of the bacterial non-ribosomal peptide indigoidine relies on the respiratory metabolic state in S. cerevisiae. Microb Cell Fact. 2018;17:193. https://doi.org/10.1186/s12934-018-1045-1.

\section{Publisher's Note}

Springer Nature remains neutral with regard to jurisdictional claims in published maps and institutional affiliations. 